\section{ON A GANGLION-NEUROMA OF THE MESENTERY.}

By Str JOHN BLAND-SUTTON, F.R.C.S. ENG., SURGEON TO THE MIDDLESEX HOSPITAT.

FOR many years I have been interested in large globular or ovoid tumours occasionally found in the subperitoneal connective tissue. Such tumours may grow in the immediate neighbourhood of the kidney or in the mesentery. To the naked eye they resemble a moderately firm uterine fibroid, and as a rule have been described as spindlecelled sarcomas (fibro-sarcomas). A few of these tumours may hate been of this nature, but many are clinically innocent. I have followed up the subsequent history of some of the patients, and they have been free from recurrence many years after operation. A few years ago Turnbull, and subsequently P. Paterson, ${ }^{1}$ published some observations on ganglion-neuromas of the mesentery. These were tumours of the size and shape of coco-nuts enucleated from the mesentery. On microscopic examination the tissue of the tumour contained nerve-cells and nerve-fibres. On becoming acquainted with this discovery I initiated a systematic histological examination of some so-called fibro-sarcomas of the abdomen in my possession, and especially one removed from the mesentery of a young woman. None contained nerve-tissue of any kind.

In 1917 a boy, aged 10, came under my care with double talipes equinus (a sequel of infantile paralysis) and a large abdominal tumour. In his fourth year an attempt was made by a surgeon to remove the trmour; in the course of the operation the capsule was found to be so beset with large veins, and the tumour itself seemed so firmly fixed to the spine, that he decided to leave it and closed the incision. The tumour grew, and as the parents wished for something more to be done, I decided to attempt its removal. When exposed by means of a free median sub-umbilical incision this tumour was found to be

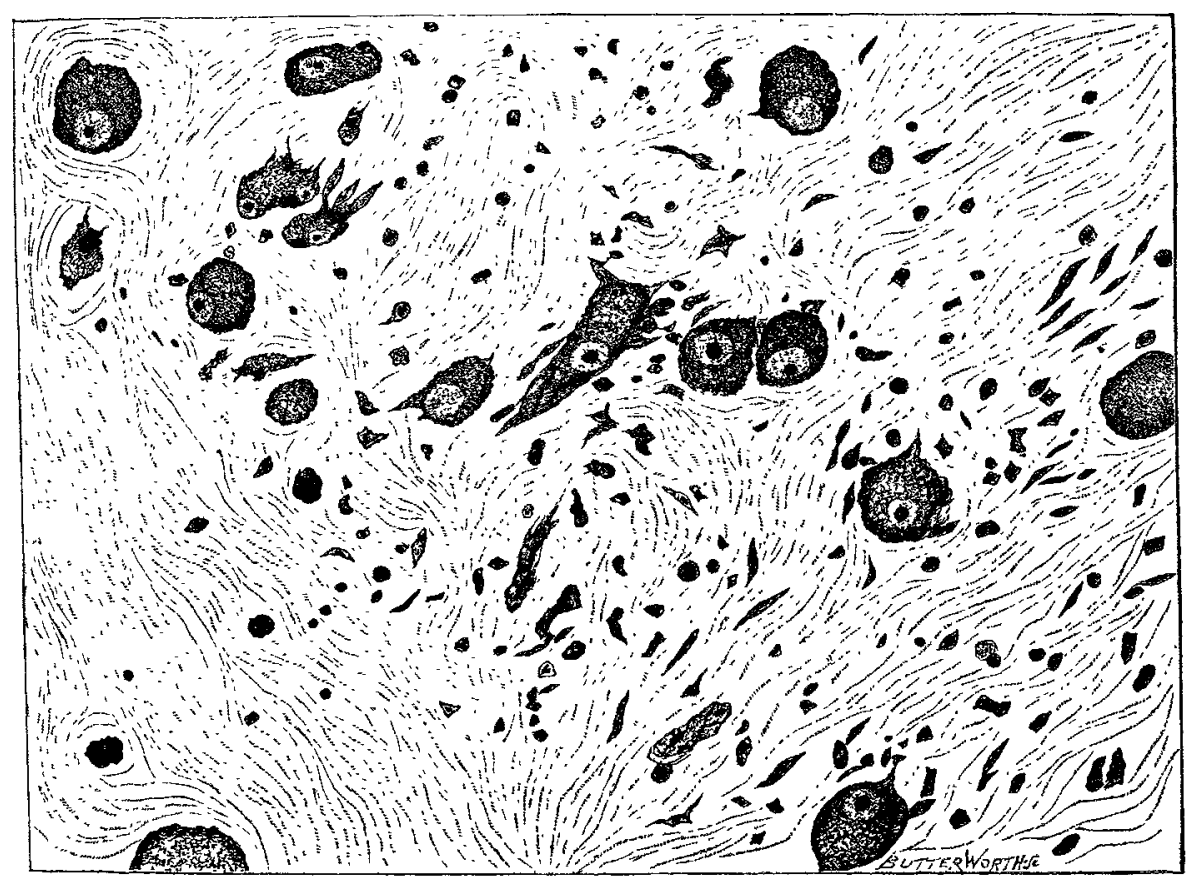

FIG. 1.-Ganglion-neuroma. Ganglion cell. Nissl's staining. ( $\times 350$.

encapsuled between the layers of the mesentery. The capsule contained a number of large veins, but the bleeding was easily controlled and the tumour shelled adolescents.

Brook-street, w. readily. The boy made a quick recovery and remains well.

The tumour, in shape and size, resembles a coco-nut and measures 15 by $10 \mathrm{~cm}$. Externally it is firm and yellowish like a uterine fibroid, but soft in the middle. I suspected it to be a ganglion-neuroma, and some pieces were prepared and examined by Dr. Browning in the Pathological Institute of the Middlesex Hospital. Nerve-cells were abundant. (Fig. 1.) Medullated nerve-fibres were displayed with the help of Levaditi's silver method. (Fig. 2.) Sections prepared from a strip of tissue involving the soft core and the periphery of the tumour displayed nerve-cells throughout.

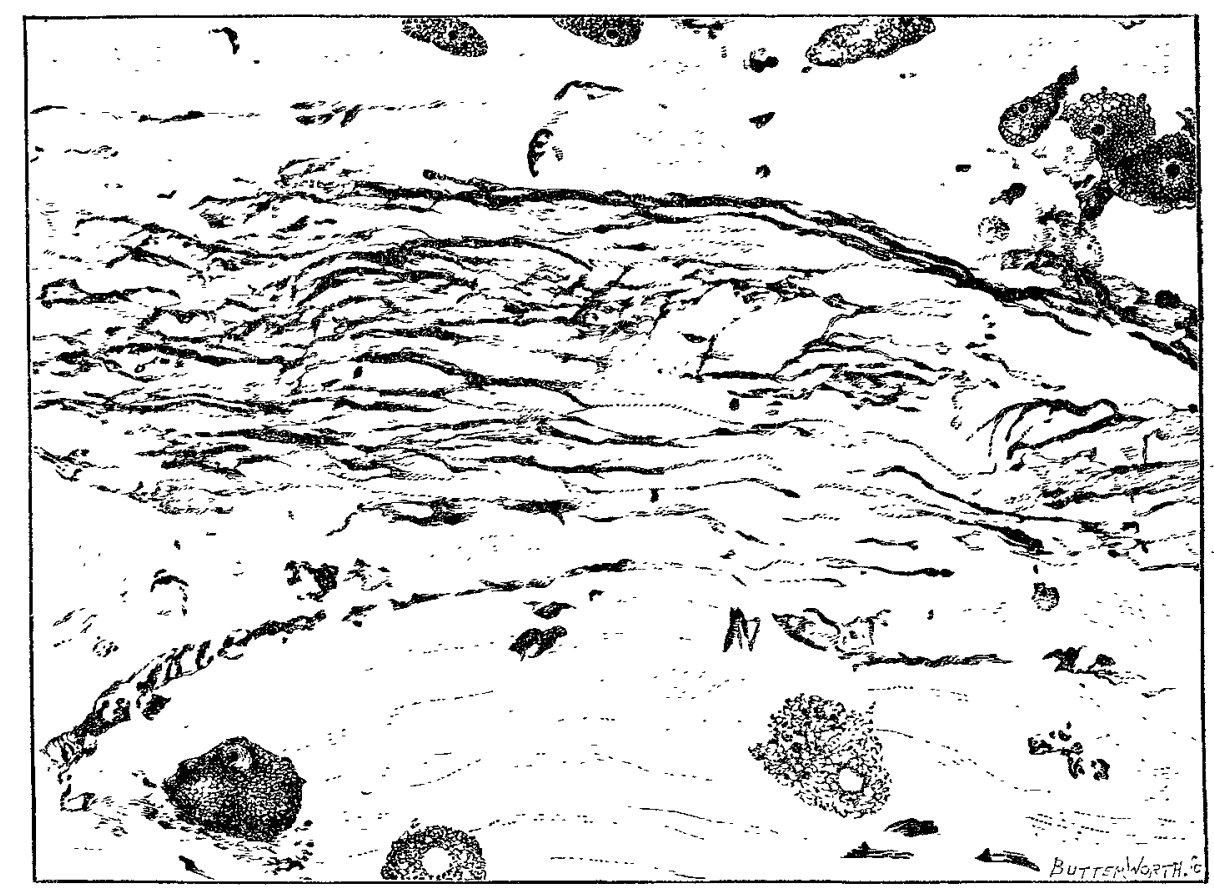

Nerve-fibres and ganglion cells. Levaditi's silver method. $(\times 800$.

As some remarkable examples of ganglion-neuromas have been described in connexion with the adrenals, I made a thorough examination of the abdomen during the operation and satisfied myself that the tumour had no connexion with these organs.

A useful paper on ganglion-neuromas of the mesentery and the adrenals has been published by John Shaw Dunn. He collected the literature and tabulated the reported cases. ${ }^{2}$ Among the 60 records tabulated by him 48 were reported since 1900 ; of these 35 were observed within the last ten years. Ganglionneuromas of large size are more common in children than adults. They are rare in the mesentery, and in this situation appear only during childhood and adolescence. Clinically they are innocent.

Ganglion-neuromas of the adrenals display malignancy in its worst forms, for they disseminate. These tumours are composed mainly of tissue resembling undifferentiated sympathetic neuroblast ; ganglion-neuromas of this type are in consequence called neuroblastomas.

It is well known that some ovarian and testicular teratomas contain nervetissue indistinguishable from the grey matter of the brain. The majority of such tumours are innocent, but some display malignancy and disseminate. It is not improbable that these ganglionneuromas are embryomas in which neuroblastic tissue preponderates, and it is well to note that the typical
mesenteric ganglion-neuromas occur in children and 


\section{TWILIGHT SLEEP: ITS ADVANTAGES AND DISADVANTAGES. ${ }^{1}$}

\section{BY GEORGE BLACKER, M.D. LOND., F.R.C.P. LOND. F.R.C.S. ENG.,}

OBSTETRIC PHYSICIAN, UNIVRRSITY COLILGE HOSPITAL; PRESIDENT OF

[AFTER some introductory remarks on the prominence given of recent years to twilight sleep, the action of scopolamine alone was considered, observations of Cushny being quoted. The death-rate from scopolamine-morphine narcosis in surgical practice was mentioned, and the fact emphasised that this combination when used without any other anæsthetic may have very dangerous results.]

\section{TECHNIQUE.}

The technique of the method of producing twilight sleep, as described by Krönig and Gauss, is, shortly, as follows The initial dose is given when the pains of the first stage are recurring regularly every four or five minutes and lasting some 30 to 45 seconds, as estimated by placing the hand upon the uterus. It consists of $1 / 150 \mathrm{gr}$. of scopolamine hydrobromide and $\frac{1}{2}$ gr. of narcophine or $\frac{1}{4} \mathrm{gr}$. of morphia hydrochloride. It is of the utmost importance that a thoroughly reliable preparation of scopolamine should be used; it is difficalt to prepare, and the various preparations vary a good deal in their action, and possibly to this fact some of the bad results which have been obtained are to be attributed. A stable preparation should be used which has been standardised. Three-quarters of an hour after the first dose a second of $1 / 150 \mathrm{gr}$. of scopolamine only is given. So far the treatment is the same for all, but the further dosage varies for each patient, and according to Gauss if good results are to be obtained must be determined by what he calls the memory test.

Scopolamine has the power not only of producing a certain degree of analgesia but also of interrupting the mental associations. It is held very strongly by those who have most experience of this method that the dosage must be regulated by the memory test, but it is instructive to note that many cbservers, including several members of the committee who took part in the recent investigation into this subject initiated by the Obstetrical Section of the Royal Society of Medicine, found the memory test unreliable and unsatisfactory. It has the further disadvantage that it requires the rousing up of the patient each time that it is applied. Gauss, however, lays great stress upon it, and insists that the success or failure of the treatment stands or falls by the observation of this one test. It is interesting to observe that the routine method of administering a certain dose of scopolamine and narcophine at certain intervals of time without any reference to the state of the patient's memory is reserved in the Freiburg clinic for those women whom they euphemistically term their "third-class patients."

When the memory test is employed, half an hour after the second injection the woman is asked if she has had an injection, or if she remembers some object which was shown her at the time when the second injection was given. If the memory is still retained a third dose of scopolamine, $1 / 200$ gr., is given, and further doses are given at varying intervals, depending upon whether the memory is retained, is dubious, or is lost.

Amnesia is the condition aimed at, and it is obvious that the application of the memory test requires a good deal of experience and intelligence on the part of the interrogator. Usually after the second or third dose the patient is unable to remember anything which has happened some 15 minutes before. During a uterine contraction the behaviour of the patient often would lead one to believe that she was appreciating the pains, but if at the end of the contraction she has no recollection of pain her condition of amuesia may be considered satisfactory. In order to lessen sensory impressions as much as possible the room should be darkened, all noises avoided, the patient's ears plugged with cotton-wool, and at the actual moment of the birth her face covered with a towel, as it has been shown that if these precautions are not observed excitement is more likely to occur.

The number of injections required varies a good deal : $3-6$ is a fair average, but in one case reported by the com mittee as many as 53 were given. The amount of the maximum dose which should not be exceeded is more important. Gauss considers $1 / 15$ gr. scopolamine the maximum, but he recommends as a rule an amount not exceeding 1/20 gr. in any one case. He has, however, given

1 Being a paper read at the opening of a discussion at the Hunterian Society on March 6th, 1918. as much as $1 / 3 \mathrm{gr}$. without any bad results. One-third of grain of morphia should never be exceeded, and only $1 / 6 \mathrm{gr}$. should be given in an ordinary case.

As 1 have mentioned, the memory test is difficult to apply, and not always to be depended upon, but so far there is nothing which can replace it with certainty. It has been suggested that use may be made of the degree of dilatation of the pupil or the presence or absence of Babinski's'reflex. Neither of these is, however, satisfactory, and if the memory test is not employed the practitioner must fall back upon his knowledge of the condition of a patient when she is sufficiently under the influence of the drug to be in a state of complete amnesia. It is important to bear in mind that the abolition of memory is what is aimed at, not the abolition of pain, and complete analgesia must be regarded as evidence of overdosage:

In the 302 cases recorded by the committee complete amnesia was obtained in some 48 per cent. and partial amnesia in some 35 per cent. In 4214 recorded cases complete amnesia is claimed in 58.9 per cent.

It is often advisable when the head is escaping over the perineum to give a little chloroform or the patient may appreciate and remember these pains, and if this occurs the lasting effect of the previous condition of amnesia is likely to be lost.

\section{EFFects of THE DRuGs.}

We may, I think, admit then that this method of scopo. lamine-morphine narcosis is capable of producing complete or partial arnnesia in some three-fourths of all suitable cases when it is carried out with a proper technique. If this is admitted, what are the objections to its general employ. ment? Before answering this question we must consider a little more fully not only its action upon the central nervous system in producing a condition of amnesia, but also its effect upon the other organs of the body, including the pelvic organs.

\section{General Effects.}

When the patient is under the influence of the drugs the most marked symptoms which may occur are congestion of the face, headache lasting for one or two days, intense thirst due to the arrest of the salivary secretion, nausea vomiting, increase in the pulse-rate, slowing of the respirations, and at times a considerable degree of restless ness with mental confusion and even delirium. In some patients the excitement takes the form of hysterical con vulsions, which are due rather to a nervous predisposition on the part of the patient than to the direct action of the drug It must not be supposed that such results are a common accompaniment of twilight sleep; they are not, but they do occur from time to time, and may form a serious complication.

Of the 135 cases recorded by Ley thirst was present in 63 per cent., nausea and vomiting in 24 per cent., restlessness in 25 per cent., mental confusion in 24 per cent, excitement in 35 per cent., and a small proportion of these last were maniacal. It is very necessary to insist upon the fact that the toxicity of scopolamine varies ver markedly in different individuals, and the effect of the firs dose upon the patient should be watched very carefully, and if any untoward symptoms arise no further dose should be given

Bardeleben maintains that the action of scopolamine is at times a dangerous one and relates a case ending fatally.

The patient in whom the action of the drug, so far as the amnesia was concerned, had boen very successful, had a severe hæemorrhage between one and two hours after her confinement, and died in a state of coma with a very feeble pulse. He regarded the case as one of intoxication from the drug, and stated that the condi

Gauss, on the other hand, states that in an experience of 1000 cases in 70 per cent. the amnesia was perfect, and that he has not met with either headache, vomiting, or cyanosis He does not admit that scopolamine is a cardiac poison, he has not experienced any modification of the pulse, and far from regarding it as contraindicated in pulmonary affec tions, on the contrary he advises its use in such cases. I the cases reported upon by the committee no noteworth alteration of the pulse-rate or respiration-rate was noted, so that it is probable that such disturbances are the exception and not the rule. At the same time it must be remembered that very marked reactions have been recorded with a small a dose as $1 / 300$ of a grain, and that there is no certain means of ascertaining the presence of any special idiosyncrass to the drug in any particular patient.

\section{Effect on Uterine Contraction.}

If we now pass to a consideration of the effect of the drugs on the uterine contraction we find a more general agreemen among different observers. [The opinions of the reporters to the Obstetrical Section and of other observers were given, and amoug other remarks the speaker said It will probably be a fair computation if we say that in some 20-30 per cent. of the cases the daration of the labour is pro- 